\title{
Stage IIIA Cutaneous Melanoma AJCC v7
}

National Cancer Institute

\section{Source}

National Cancer Institute. Stage IIIA Cutaneous Melanoma A/CC v7. NCI Thesaurus.

Code C86049.

Stage IIIA includes: (T1-4a, N1a, M0); (T1-4a, N2a, M0). T1-4a: Non-ulcerated cutaneous melanoma of any thickness. N1a: Cutaneous melanoma with micrometastasis in one regional lymph node. N2a: Cutaneous melanoma with micrometastases in 2-3 regional lymph nodes. M0: No detectable evidence of distant metastases. (from AJCC 7th Ed.) 